\title{
Optimizing Dietary Fat to Reduce Breast Cancer Risk: Are we there Yet?
}

\author{
Lynda Michele Evans ${ }^{1}$ and Robert William Hardy ${ }^{*}, 2$ \\ ${ }^{I}$ Department of Physiology and Biophysics, University of Alabama at Birmingham, USA \\ ${ }^{2}$ Department of Pathology, University of Alabama at Birmingham, USA
}

\begin{abstract}
For over 70 years, long chain fatty acids have been implicated in the development and progression of breast cancer. Although the exact role remains to be elucidated, dietary factors have been implicated in approximately $35 \%$ of cancer deaths. Currently, biomarker, animal and in vitro studies suggest that the individual fatty acids have differing roles in the promotion or prevention of breast cancer development and progression. The goal of this review is to assess epidemiological, animal and cellular studies with respect to the role of dietary long chain fatty acids in breast cancer risk. Subsequently we identify the common findings in these studies, discuss important factors that may influence human studies and evaluate the current dietary fat recommendations with respect to these findings.
\end{abstract}

Keywords: Dietary, fatty acids, breast cancer.

\section{INTRODUCTION}

In 1981, Doll and Peto estimated that dietary factors could be attributed to $35 \%$ of cancer deaths, with a range of $10 \%$ to $70 \%$ [1]. For breast cancer, dietary fat has remained a controversial, modifiable factor since Tannenbaum's hallmark studies investigating the role of dietary fat on breast cancer development published in 1942 [2]. These studies were performed on rodents and demonstrated that a high fat diet increased susceptibility to mammary tumors. Then, 1976, Carroll showed the average fat intake of a country was correlated to the breast cancer mortality rate. Furthermore, he showed a positive correlation between breast cancer and fat intake derived from animal sources but no correlation for fat derived from vegetable sources [3]. Although the study did not control for cultural or geographical variables such as exercise, life span, or sun exposure, these results suggested the possibility that not only the amount of fat in the diet, but also the source of the fat may affect breast cancer development. Since then numerous epidemiology and clinical studies have produced conflicting results. Animal and cell culture studies, on the other hand, show that it is not only the amount of fat, but also the concentration of individual fatty acids that affect the development and growth of mammary tumors. The goal of this minireview is to summarize the key points in the field of dietary fat and breast cancer, with a specific focus on the long chain fatty acids, and to put them in the context of current dietary guidelines.

\section{Long Chain Fatty Acids}

Long chain fatty acids are carboxylic acids composed of a carboxyl head group followed by a long hydrocarbon chain [4]. Saturated fatty acids such as palmitic acid or palmitate (C16:0) and stearic acid or stearate (C18:0) have no double

*Address correspondence to this author at the Department of Pathology, University of Alabama at Birmingham, 701 South 19th St., LHRB Rm 531, Birmingham, AL 35294, USA; Tel: 205-934-9925; E-mail: rwfh1@uab.edu bonds along their hydrocarbon chains whereas unsaturated fatty acids have at least one double bond (Fig. 1). Unsaturated fatty acids are further characterized by the number and location of the double bonds - monounsaturated fatty acids have one double bond and polyunsaturated fatty acids have multiple double bonds. The final carbon on the hydrocarbon chain is known as the omega carbon. The number of carbons between the omega carbon and the first double bond determines the type of the unsaturated fatty acid. For example, the monounsaturated fatty acid oleate (C18:1) has its first double bond 9 carbons from the omega carbon and therefore is an omega-9 fatty acid. Linoleate (C18:2) is a polyunsaturated fatty acid whose first double bond is 6 carbons from the omega carbon and is therefore an omega-6 fatty acid [4]. See Table 1 for a summary of the characteristics of each long chain fatty acid. Dietary fatty acids contain fatty acids with both cis and trans double bonds. These trans fatty acids are largely produced by industry and in the US contribute about $2-3 \%$ of energy intake [5].

In biological systems, fatty acids serve several major roles including being a major component of the phospholipids and glycolipids, precursors to eicosanoids (hormone-like lipid molecules), they can be esterified to form diacylglycerol, a $2^{\text {nd }}$ messenger signaling molecule, or triacylglycerols for energy stores used in times of famine and physiological stress, and they can affect protein function by covalently binding to the amino acid chain (acylation) [6]. Fatty acids are either made endogenously or consumed in food. Humans lack the ability to make two fatty acids essential to normal physiological functions - linoleate and linolenate $(\mathrm{C} 18: 3)$ - and therefore these must be consumed through the diet.

Serum fatty acid profiles in humans vary somewhat depending on the country in which the study was done. In healthy US adults, fasting serum non-esterified fatty acid concentration was determined to be $\sim 750 \mu \mathrm{M}$ [7]. Linoleate, oleate and palmitate are the most abundant in the plasma, followed by arachidonate and stearate. The approximate 
A

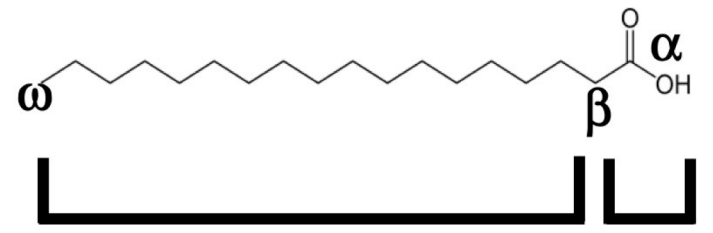

\section{Hydrocarbon \\ Chain \\ Carboxyl \\ Head Group}

B
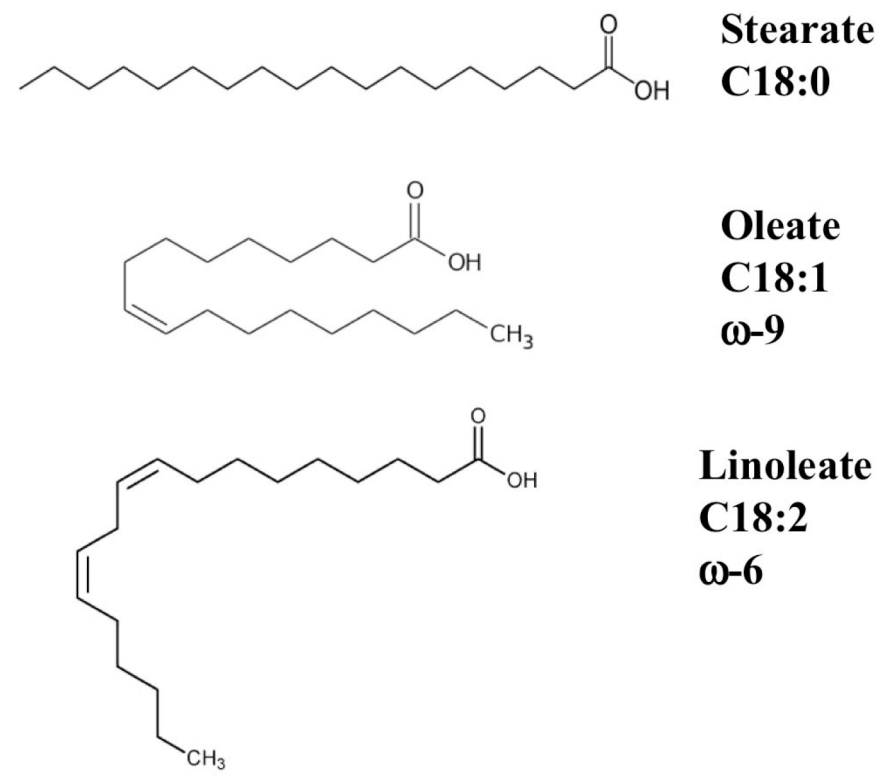

Fig. (1). Fatty Acid Nomenclature. A) Fatty acids are composed of a carboxyl head group followed by a hydrocarbon-like chain. The first carbon on the head group is known as the $\alpha$ carbon, whereas the second is the $\beta$ carbon, etc. The final carbon is known as the $\omega$ carbon. Unsaturated fatty acids are classified based on the position of the first double bond from the $\omega$ carbon. B) Saturated fatty acids, such as stearate, have no double bonds. Monounsaturated fatty acids, such as oleate, have one double bond and polyunsaturated fatty acids like linoleate have more than one double bond. Oleate is an $\omega-9$ because the double bond occurs 9 carbons from the omega carbon whereas linoleate is an $\omega-6$ fatty acid.

abundance of these non-esterified serum fatty acids in the US population is as follows: linoleate, $26 \%$, oleate, $24 \%$, palmitate, $22 \%$, arachidonate, $8 \%$ and stearate, $7 \%[8]$. Linolenate concentrations are below $5 \mu \mathrm{M}$ and arachidonate below $10 \mu \mathrm{M}$, regardless if the subjects fasted [9].

Metabolism: In biological systems, fatty acids serve several major roles - they are a major component of the phospholipids and glycolipids, they are precursors to eicosanoids (hormone-like lipid molecules), they can be esterified to form diacylglycerol, a $2^{\text {nd }}$ messenger signaling molecule, or triacylglycerols, energy stores used in times of famine and physiological stress, and they can affect protein function by covalently binding to the amino acid chain (acylation) [6]. Fatty acids are either made endogenously or

Table 1. Classification of Long Chain Fatty Acids

\begin{tabular}{|c|c|c|c|c|}
\hline Fatty Acid & Common Name & IUPAC Name & Type & Omega Class \\
\hline \hline C16:0 & Palmitate; Palmitic Acid & hexadecanoic acid & Saturated & N/A \\
\hline C18:0 & Stearate; Stearic Acid & Octadecanoic acid & Saturated & N/A \\
\hline C18:1 & Oleate; Oleic Acid & cis-9-octadecenoic acid & Monounsaturated & Omega-9 \\
\hline C18:2 & $\alpha$-Linoleic Acid; Linoleic Acid; Linoleate & cis, cis-9,12-octadecadienoic acid & Polyunsaturated & Omega-6 \\
\hline C18:3 & $\alpha$-Linolenic Acid; Linolenic Acid; Linolenate & $9,12,15$-octadecatrienoic acid & Polyunsaturated & Omega-3 \\
\hline C20:4 & Arachidonic Acid; Arachidonate & $5,8,11,14$-icosatetraenoic acid & Polyunsaturated & Omega-6 \\
\hline C20:5 & Eicosapentaenoic acid; EPA & $5,8,11,14,17$-icosapentaenoic acid & Polyunsaturated & Omega-3 \\
\hline C22:6 & Docosahexaenoic acid'DHA & $4,7,10,13,16,19$-docosahexaenoic acid & Polyunsaturated & Omega-6 \\
\hline
\end{tabular}


consumed in food. Humans lack the ability to make two fatty acids essential to normal physiological functions - linoleate and linolenate $(\mathrm{C} 18: 3)$ - and therefore must be consumed through the diet.

Synthesis of fatty acids occurs when carbohydrate levels are high and fatty acid levels are low. The process is controlled by two enzymes - acetyl CoA carboxylase (ACC) and fatty acid synthase (FAS). ACC converts acetyl CoA to malonyl CoA, one of the basic building blocks used by FAS to make fatty acids [10]. Approximately $80 \%$ of the fatty acids produced by FAS are palmitate, whereas stearate and myristate comprise $10 \%$ each [11]. On the other hand, degradation of fatty acids occurs in the mitochondria and is known as mitochondrial $\beta$-oxidation. $\beta$-oxidation takes fatty acids and breaks them down into acetyl-CoAs making it essentially the reverse of fatty acid synthesis. The carnitine palmitoyltransferase 1 (CPT1) is mitochondrial outer membrane protein that, along with $\mathrm{CPT} 2$ on the inner mitochondrial membrane, transports fatty acids into the mitochondrial lumen [12]. CPT1 is inhibited by malonyl CoA whereas ACC is inhibited by insulin ensuring that the synthesis and degradation processes do not occur at the same time [6].

Fig. (2) is an example schematic of the fatty acid metabolism of stearate, a long chain dietary saturated fatty acid. When stearate enters the cell (or is synthesized) it encounters an enzyme known as acyl-CoA synthetase (ACS) [13]. ACS converts hydrophobic fatty acids into their hydrophilic Co-A derivatives. These hydrophilic molecules are the basic building blocks of phospholipids, phosphatidylinositides, acylglycerols, and sphingomyelins. This occurs through the formation of precursors such as lysophatidate (lysophatidic acid) and phosphatidate (phosphatidic acid). The omega-3 and omega-6 fatty acids follow a metabolism similar to that of stearate (Fig. 2). However, they can also be used to synthesize eicosanoids, as depicted in Fig. (3) [14].

\section{DIETARY FAT RECOMMENDATIONS OF THE AMERICAN DIETETICS ASSOCIATION (ADA) AND THE DIETICIANS OF CANADA (DC)}

According to the ADA and DC, total fat intake should range between 20 and $35 \%$ of total energy intake. Within this recommendation, 3 to $10 \%$ of total fat should come from the omega- 6 polyunsaturated fatty acids and 0.6 to $1.2 \%$ from omega-3 polyunsaturated fatty acids. Saturated fatty acids should be consumed as little as possible and make up for no more than $10 \%$ of total fat, with recommendations as low as $3 \%$. Monounsaturated fatty acids should be consumed to make up for the dietary fat percents not met by the other fatty acids [15].

In recent years, numerous dietary studies and recommendations have shown that a high omega-6/omega-3 ratio promotes increases in viscosity of the blood, vasoconstriction of the blood vessels, and platelet aggregation. There is also a correlation between increased omega-6/omega-3 ratios and the risk of diabetes [16]. These negative health effects are often attributed to competition of linolenate and linoleate for the enzymes that lead to the formation of the eicosanoid precursors, eicosapentaenoic acid (EPA) and arachidonate, respectively. Many of the omega-3 derived eicosanoids are thought to have antiinflammatory and anti-thrombotic effects whereas those derived from omega- 6 fatty acids have pro-inflammatory, pro-thrombotic and carcinogenic effects [14]. Furthermore, as the intake of omega-3 fatty acids increases, they have been shown to displace the omega- 6 fatty acids in terms of not just eicosanoids, but also other lipid by-products such as phospholipids, and vice versa [17].

The current ADA recommendations state that the lower limit of the omega6/omega 3 ratio is $3 / 1$ and the upper limit is $16 / 1$. In 2000, the National Institutes of Health hosted The Workshop on the Essentiality of and Recommended Dietary Intakes (RDIs) for omega-6 and omega-3 Fatty Acids. During this workshop, the attendees concluded humans

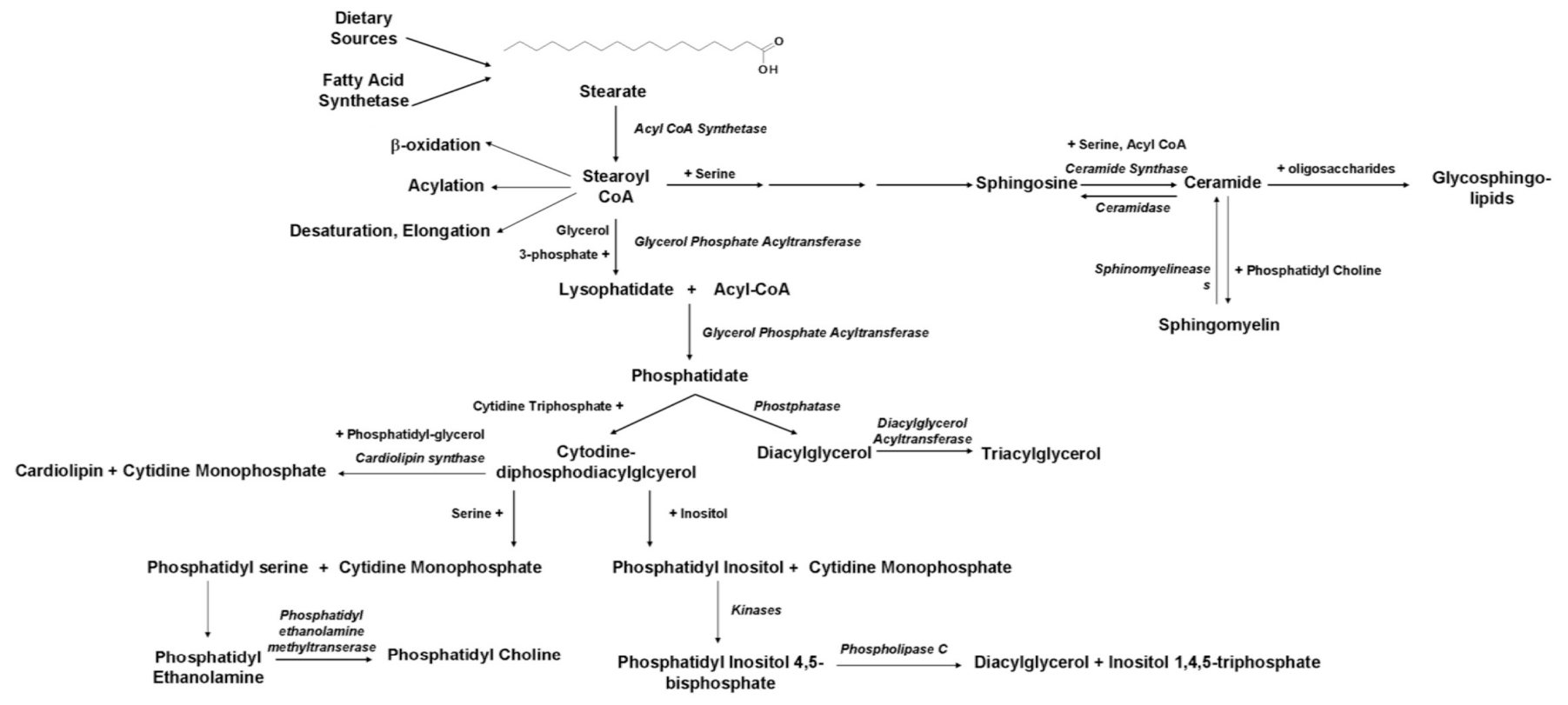

Fig. (2). Metabolism of stearate. 


\section{Omega-6}

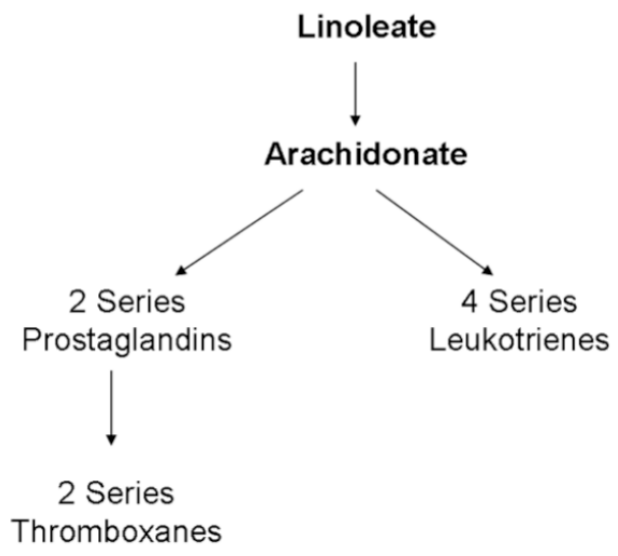

Omega-3

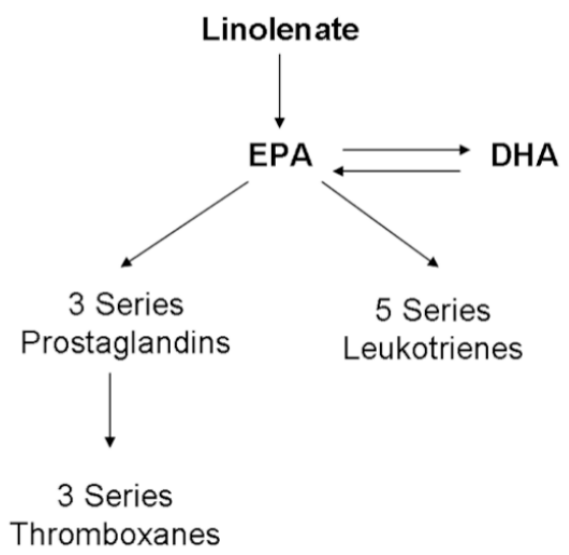

Fig. (3). Omega-6 and Omega-3 Fatty Acid Metabolism. Omega-3 and omega-6 fatty acids are converted into EPA and arachidonate, respectively. They are then converted to various eicosanoids, including prostaglandins, leukotrienes, and thromboxanes, among others.

should consume 2-3\% energy from linolenate, an omega-3 fatty acid, daily, $1 \%$ from linoleate, an omega- 6 fatty acid, and at least $0.3 \%$ docosahexaenoic acid (DHA) and EPA [18]. The recommended omega 6/omega 3 ratio based on these fat intakes ranges from $1.2 / 1$ to $2.3 / 1$. The ratio recommended by the workshop has been suggested by others to be the most beneficial in terms of human health [17].

\section{EPIDEMIOLOGY}

Since the publication of Carroll's initial correlative studies, many case-controlled and cohort studies have been performed, analyzing the effects of total fat, saturated fat, monounsaturated fat, and polyunsaturated fat on breast cancer risk. Many of these studies have been summarized in four meta-analyses and have spawned four multi-centered, large scaled cohort studies. These studies, which are discussed below, are controversial, and reveal conflicting results.

\section{Meta-Analyses of Dietary Fat Research}

To date, four meta-analyses analyzing multiple cohort and case-controlled studies have been published examining the effect of dietary fat on breast cancer. Two of these analyses found no effect of dietary fat on breast cancer development - a meta-analysis of 21 cohort and casecontrolled studies and a meta-analysis of 8 cohort studies $[19,20]$. A meta-analysis of 12 case-controlled studies found a positive association of total fat, saturated fat, and monounsaturated fat and breast cancer risk in postmenopausal women [21]. A more recent analysis of 14 cohort and 31 case-controlled studies found similar results, with a positive association seen with total fat and saturated fat intake and breast cancer risk [22]. The latter analysis included a total of over 25,000 cases of breast cancer in 20 countries. Overall the meta-analyses are suggestive of an effect of total fat and saturated fat on breast cancer risk but are not conclusive.

\section{Large Multi-Center Cohort Studies}

Several large scale studies have been arranged in recent years to investigate the role of dietary fat on breast cancer risk. Unlike the case-controlled studies that often centered around one region, these studies were either national or continental studies. Such a large population may be more representative of society than the smaller scale studies. These include the European Prospective Investigation into Nutrition and Cancer (EPIC) as well as three interventional studies - United States' Women's Health Initiative (WHI) that measured the risk of breast cancer following a reduction in dietary fat, the Women's Intervention Nutrition Study (WINS) and Women's Healthy Eating and Living (WHEL) in the United States which measured the effect of dietary fat on relapse and survival in patients previously diagnosed with breast cancer. The results of these studies that relate to breast cancer and fat intake are explained below.

\section{EPIC}

The EPIC study began in 1993 with data being collected from 23 centers in 10 European countries. The study consisted of 521,468 participants, 366,521 of whom were women. During the duration of the study, several papers were published examining the role of various nutrients on breast cancer development. Of 319,826 women analyzed, 7119 developed breast cancer. Within the subgroup of those who developed breast cancer, no association was seen between cancer risk and total fat intake when comparing the highest and lowest quartiles of fat intake $(\mathrm{HR}=1.02 ; 95 \%$ $\mathrm{CI}=0.90-1.17 ; \mathrm{p}$ for trend $=0.601)$, although a weak positive association was observed with saturated fat intake $(\mathrm{HR}=1.13 ; 95 \% \mathrm{CI}=1.00-1.27 ; \mathrm{p}$ for trend $=0.038)$ but not monounsaturated $(\mathrm{HR}=1.05 ; 95 \% \mathrm{CI}=0.92-1.20 ; \mathrm{p}$ for trend $=0.254)$ or polyunsaturated fatty acids $(\mathrm{HR}=0.97$; $95 \% \mathrm{CI}=0.88-1.07$; $\mathrm{p}$ for trend $=0.372$ ) [23].

Consistent with no effect of polyunsaturated fatty acids, one study examined the fish consumption of 310,671 women, 4776 of whom developed invasive breast cancer. No association was found between total fish, lean fish, or fatty fish and breast cancer development. [24]. Interestingly, analysis of individual centers had different effects in terms of individual fatty acids and breast cancer risk. Data from the Cambridge center found no association between saturated fat and breast cancer risk when comparing the results of the 
food-frequency questionnaire $(\mathrm{HR}=1.10 ; 95 \% \mathrm{CI}=0.94$ $1.29 ; \quad \mathrm{p}=0.23)$ although women who consumed approximately 35 grams of fat a day from dairy had twice the risk of developing breast cancer than those who consumed 10 grams or less from dairy $(\mathrm{HR}=1.22 ; 95 \% \mathrm{CI}=$ 1.06-1.40; $\mathrm{p}=0.005$ ) [25]. On the other hand, data collected from 15,351 German women at the Potsdam location suggested the 137 cases of invasive breast cancer that developed were positively associated with total fat intake. Additionally, the breast cancer cases were positively correlated with saturated fat, monounsaturated fat, and polyunsaturated fat (both omega-3 and omega- $6 ; \mathrm{p}<0.0001$ for all groups). It is worth noting, however, that dietary assessments were only performed at the beginning of the study. Therefore, the study does not account for any dietary changes that occurred between the beginning of the study and the time of diagnosis [26].

\section{Interventional Studies}

\section{WHI}

The Women's Health Initiative Dietary Modification Trial was the first large scale randomized trial to test the effects of a low fat diet on breast cancer risk. 48,835 postmenopausal women were enrolled at 30 sites around the United States between 1993 and 1997. Of those enrolled, 19,451 women were randomized into a dietary intervention group whereas 29,294 were in the comparison group. The women in the dietary intervention group were counseled to lower their fat consumption by $50 \%$ - from $40 \%$ of total energy intake to approximately $20 \%$ of total energy intake [27]. Women were then followed for 8.1 years and the incidences of various cancers and heart diseases were recorded [28]. The results for the WHI study were highly anticipated and, to the surprise of the research community, no effect was seen on the risk of invasive breast cancer between the dietary intervention and comparison groups [2729]. There was a $9 \%$ decrease in breast cancer incidence in the intervention group, but the results were not significantly different from the control group ( $\mathrm{HR}=0.91 ; 95 \% \mathrm{CI}=0.83$ 1.01; unweighted $\mathrm{p}$-value $=0.07)$ [28]. Perhaps even more surprising, the women who were in the highest quartile of basal fat intake saw a decreased risk for invasive breast cancer $(\mathrm{HR}=0.78 ; 95 \% \mathrm{CI}=0.64-0.95$; interaction $\mathrm{p}$ value $=0.04)$ [28]. Interestingly, an unexpected, significant decrease in ovarian cancer was seen in the cohort of women on the lower fat diet $(\mathrm{HR}=0.83 ; 95 \% \mathrm{CI}=0.60-1.14$; $\mathrm{p}=0.03$ by weighted log rank test) [30].

Since the release of the results, several issues have been raised about the study [31]. The study design called for a $50 \%$ difference in fat intake between the intervention and control groups. In reality, the study saw a $25 \%$ difference after year one, $25 \%$ difference after year three and a $24 \%$ difference after year five. It is thought this inability to reach the targeted fat reduction may account for the unexpected results. Furthermore, the enrollment period needed to meet the participant goal of the study took longer than anticipated. As a result, the average follow-up period was 8.1 years as compared to the original goal of 9 years. Once again, this unanticipated decrease is thought to account for the lack of an effect of the low fat diet on breast cancer risk [27].

\section{WINS}

Unlike the WHI and EPIC studies, the WINS study was designed to determine the effect of a low fat diet on breast cancer reoccurrence in patients with early staged, surgically removed breast tumors [32]. 2,437 women aged 48 to 79 were recruited at 39 sites around the United States to participate. Of those enrolled, 975 were assigned to the dietary intervention group that aimed to reduce dietary fat to $15 \%$ of the diet where as 1462 were assigned to the control group and were not instructed to change their diet [33].

After one year, those patients on the low fat, intervention diet decreased their total fat intake by approximately $10 \%$, resulting in a decrease in saturated, monounsaturated, and polyunsaturated fat compared to their control counterparts [33]. This decrease remained significant for the $\sim 5$ years of the study [34]. In terms of breast cancer recurrence and survival, no difference was observed in overall survival between the control and dietary intervention groups ( $\mathrm{HR}=$ $0.89 ; 95 \% \mathrm{CI}=0.65-1.21 ; \mathrm{p}=0.56)$. However, decreases in relapse-free survival events (defined as breast cancer reoccurrence at any site; $\mathrm{HR}=0.76 ; 95 \% \mathrm{CI}=0.60-0.98$; $\mathrm{p}=0.077$ by stratified long rank test, $\mathrm{p}=0.034$ by adjusted Cox model analysis), recurrence free-survival events (defined as breast cancer recurrence at any site excluding contra-lateral breast cancer $\mathrm{HR}=0.71 ; 95 \% \mathrm{CI}=0.53-0.94$; $\mathrm{p}=0.05$ by stratified log rank test), and disease-free survival events (defined as a secondary invasive breast cancer, excluding basal and squamous skin cancers; $\mathrm{HR}=0.81 ; 95 \%$ $\mathrm{CI}=0.65-0.99 ; \mathrm{p}=0.078$ by stratified long rank test) were observed in the intervention groups compared to the control groups [35]. Interestingly, this beneficial effect of reduced dietary fat on relapse-free survival was greater in estrogen receptor negative breast cancer $(\mathrm{HR}=0.58 ; 95 \% \mathrm{CI}=0.37$ $0.91 ; \mathrm{p}=0.018)$ than estrogen-receptor positive breast cancer $(\mathrm{HR}=0.85 ; 95 \% \mathrm{CI}=0.63-1.14 ; \mathrm{p}=0.277)$ [35]. This study was among one of the first large scale studies to show that modifications in dietary fat could affect survival in patients previously diagnosed with breast cancer, and suggested a potential treatment for patients with the often hard to treat estrogen receptor negative breast cancer [36].

\section{WHEL}

The Women's Healthy Eating and Living Randomized Trial was designed in a manner similar to the WINS study. Participants were women aged 18 to 70 who had previously had a surgically removed primary breast tumor. They were enrolled at 7 sites around the United States between 1995 and 2000. The 3088 participants were divided into a dietary intervention group $(n=1537)$ or a control group $(n=1551)$. Those in the dietary intervention group were advised to take a diet high in fruits and vegetables and low in fat - the fat intake goal was $15-20 \%$ of total caloric intake. Those in the control group were advised to follow the 5-a-day plan (5 portions of fruit and vegetables per day). Those in the dietary intervention group had a significantly lower fat intake throughout the experiment compared to those in the control group - by year 4, a 13\% decrease in fat intake was observed $(\mathrm{p}<0.001)$. Interestingly, no difference in breast cancer relapse $(\mathrm{HR}=1.13 ; 95 \% \mathrm{CI}=0.81-1.58)$ or survival $(\mathrm{HR}=$ $0.98 ; 95 \% \mathrm{CI}=0.64-1.49$ ) was observed between the two groups [37].

Summary: In the large cohort studies the EPIC study found a weak association between saturated fat and breast 
cancer. Overall the interventional studies showed no significant effect from reducing dietary fat intake although the WHI study which looked at first occurrence of breast cancer was suggestive with a $9 \%$ non-significant decrease and the WINS study showed a significant beneficial effect in ER $\alpha$-negative breast cancer patients.

Thus epidemiological studies are suggestive that saturated fat is associated with breast cancer risk although an association for total fat remains inconclusive.

\section{ACCURACY OF DIETARY STUDIES}

The variability observed in cohort and case controlled studies has often been attributed to methodological issues. Study design issues can include inaccurate dietary recall (breast cancer patients often report higher fat intake throughout life than controls), and lack of control for other health factors such as alcohol intake, body size, and menopausal status. Additionally, many have questioned the accuracy and validity of food frequency questionnaires used to assess dietary habits. Such questionnaires often ask people to recall dietary patterns for short periods of time in their life and may not accurately represent one's lifetime dietary habits. Some questionnaires ask participants to assess dietary habits many years prior (i.e. middle aged women recalling adolescent dietary habits) and such reports may be largely inaccurate. For interventional studies the consistent inability of subjects/patients to achieve the targeted reductions in fat intake raise the question of how low their dietary fat intake can be reduced. Finally, questions have been raised in cohort studies about the duration of the follow-up period. It is possible that participants are not assessed long enough to see a true effect between dietary fat and cancer [38].

\section{DIETARY BIOMARKERS OF FATTY ACID INTAKE}

Due to the issues associated with dietary recall studies, and other issues including variability of dietary fat absorption by the intestine and metabolism (i.e. bioavailability) many scientists are using biomarkers of fatty acid intake to draw conclusions concerning fat intake and breast cancer risk. Data obtained by actually measuring individual fatty acid composition of adipose tissue, erythrocyte membranes, serum and plasma provides quantitative measurements independent of energy intake that reflect post-absorptive, bioavailable amounts of fat consumed. This eliminates inadequacies of food frequency questionnaires, food composition tables, and nutrient databases.

These so-called biomarkers include the fatty acid composition of triglycerides, phospholipids and cholesterol esters in adipose tissue, serum/plasma, and erythrocytes. One meta-analysis was published of 13 studies that examined breast cancer risk in comparison to fatty acid content of adipose tissue in all studies except one which used serum fatty acids from phospholipids. In this meta-analysis, total saturated fat $(\mathrm{RR}=1.26 ; 95 \% \mathrm{CI}=1.10-1.45)$ and total monounsaturated fat $(\mathrm{RR}=2.20 ; 95 \% \mathrm{CI}=193-2.52)$ were associated with an increase in breast cancer risk in cohorts of postmenopausal women. On the other hand, total polyunsaturated fat, both omega $6(\mathrm{RR}=0.67 ; 95 \% \mathrm{CI}=$ $0.59-0.75)$ and omega $3(\mathrm{RR}=0.58 ; 95 \% \mathrm{CI}=0.58-0.64)$, were associated with a decrease in breast cancer risk in cohorts of postmenopausal women. As for individual fatty acids, palmitate $(\mathrm{RR}=1.89 ; 95 \% \mathrm{CI}=1.0-2.10)$, oleate $(\mathrm{RR}$ $=1.45 ; 95 \% \mathrm{CI}=1.09-1.94)$, and linolenate $(\mathrm{RR}=1.14$; $95 \% \mathrm{CI}=1.03-1.26)$ were associated with an increase in breast cancer risk whereas stearate $(\mathrm{RR}=0.68 ; 95 \% \mathrm{CI}=$ $0.61-0.76)$, EPA $(\mathrm{RR}=0.91 ; 95 \% \mathrm{CI}=0.86-0.95)$, DHA $(\mathrm{RR}=0.66 ; 95 \% \mathrm{CI}=0.59-0.73)$, and linoleate $(\mathrm{RR}=0.88$; $95 \% \mathrm{CI}=0.78-0.98)$ were associated with a decreased risk also in postmenopausal women cohort studies [39]. No significant differences were seen in the case control studies. However similar results were obtained from a subsequent case-controlled study measuring erythrocyte fatty acids relative to breast cancer risk based out of Shanghai, China. Palmitate concentration correlated to breast cancer risk (OR $=2.18 ; 95 \% \mathrm{CI}=1.14-4.15 ; \mathrm{p}=0.004)$ whereas no effect was observed with stearate $(\mathrm{OR}=1.26 ; \mathrm{RR}=0.68-2.3 ; \mathrm{p}=$ $0.83)$, oleate $(\mathrm{OR}=1.28 ; 95 \% \mathrm{CI}=0.72-2.27 ; \mathrm{p}=0.6)$, or linolenate $(\mathrm{OR}=0.99 ; 95 \% \mathrm{CI}=0.54-1.82 ; \mathrm{p}=0.59)$ and $\mathrm{a}$ negative effect was observed with EPA $(\mathrm{OR}=0.45 ; 95 \% \mathrm{CI}$ $=0.26-0.77 ; \mathrm{p}=0.003)$, DHA $(\mathrm{OR}=0.61 ; 95 \% \mathrm{CI}=0.36-$ $1.04 ; \mathrm{p}=0.09)$, and linoleate $(\mathrm{OR}=0.67 ; 95 \% \mathrm{CI}=0.37-$ $1.21 ; \mathrm{p}=0.02$ ) [40]. It should be kept in mind that these studies are relatively few in number compared to the epidemiology studies. However the cohort studies are preferable due to their prospective, longitudinal, and multiple measurement design lending credibility to the results. The results are interesting if one thinks of the suggestion of saturated fat being linked to breast cancer found by epidemiology studies compared to the biomarker marker studies. The later clearly show a risk for breast cancer associated with palmitate but a protective or neutral effect was shown with stearate. Thus the balance of palmitate to stearate may be an important indicator of breast cancer risk rather than total saturated fat.

\section{DIETARY FAT STUDIES IN RODENT MODELS}

Although there are extensive studies on dietary fat and breast cancer risk there is only a suggestion of an effect of saturated fat. There are fewer biomarker studies however that support the epidemiological studies but suggest that individual saturated fatty acids differ dramatically in their effects. There are many animal studies that have investigated the effects of dietary fatty acids on breast cancer. These studies have clearly shown an effect of individual fatty acids on spontaneous tumor development, carcinogen induced carcinoma, and metastasis.

\section{Primary Tumor Studies}

In 1942, Albert Tannenbaum published a study in which DBA mice were fed a high fat diet derived from hydrogenated cottonseed oil, which contains largely linoleic acid, developed more spontaneous tumors than their control counterparts. When the diets were initiated earlier, the effect was greater, indicating that the duration and/or timing of fatty acid exposure could affect tumorigenesis [2]. Unfortunately, the individual concentrations of fatty acids in the diets used by Tannenbaum were not reported. Nevertheless, this was the first study that suggested that not only the amount of fat in the diet but also the time of exposure could affect breast cancer risk.

Since the initial studies, over 100 dietary fat studies have been performed in rodent models. Many of these have shown 
that the amount of fat in the diet correlates positively to breast cancer development. More specifically, fats derived from vegetable oils have been shown to increase cancer in spontaneous models, chemically induced models and metastasis models. Similar results were observed with natural saturated fatty acid sources such as beef tallow and lard. A threshold affect has been proposed in which increasing the concentration of fatty acid past a certain percentage does not subsequently increase tumor yield. More studies are necessary to determine if this is accurate [41].

The amount of fat the animals are exposed to also dictates the number of carcinogen-induced tumors. When animals were fed either a $5 \%$ fat diet or a $20 \%$ fat diet derived from corn oil ad libitum and injected with NMU, more animals developed tumors on the $20 \%$ fat diet. When diets were restricted to 50-59 kilocalories/day, there was no difference in tumor incidence between the diets. This suggests that not only is the amount of food in the diet a factor in determining tumor incidence, but also the amount of energy available to the animals [42].

Along with the amount of fat in the diet, the type of fat has also been implicated in the development of mammary cancer in animal studies. However, one of the major challenges in dietary studies is determining if the observed effect is due to an increase in one fatty acid or a decrease in another. To address this issue, Tinsley et al. analyzed the effect of 20 different diets composed of various concentrations of natural fats and oils to determine the effect of fat on spontaneous mammary tumor development in $\mathrm{CH} 3$ mice. Using linear regression, the role of individual fatty acids on mammary cancer development was determined. Linoleate (C18:2) was the most significantly associated with an increase in tumor incidence and palmitate (C16:0) was also associated with increased incidence. Laurate (C12:0), myristate $(\mathrm{C} 14: 0)$, oleate $(\mathrm{C} 18: 1)$ and linolenate $(\mathrm{C} 18: 3)$ had little effect on tumor development. Finally, stearate (C18:0) was substantially associated with a decrease in tumor incidence [43].

Animals fed a largely polyunsaturated diet $(18.6 \%$ total fat $-59 \%$ linoleate, $27 \%$ oleate) before and after 7,12Dimethylbenz(a)anthracene (DMBA) administration had more tumors compared to animals fed a high saturated fat diet $(18.6 \%$ total fat $-37 \%$ oleate, $28 \%$ palmitate, $19 \%$ stearate). Interestingly, if animals were placed on the polyunsaturated diet before DMBA administration and switched to the high saturate diet after administration, they developed fewer tumors than those animals placed on the polyunsaturated diet throughout. Furthermore, when animals were fed a saturated diet before and a polyunsaturated diet after DMBA administration, they developed more tumors than the animals fed the high saturated diet throughout. These results indicate that polyunsaturated fats affect the development of mammary tumors only when they are fed post-carcinogen injection, suggesting that polyunsaturated fatty acids effect the development of breast cancer during the promotion phase [44].

Interestingly, despite evidence that saturated fats may induce tumor growth, a diet enriched with stearate has been shown to delay tumor development in $\mathrm{A} / \mathrm{St}$ mice [45]. Similarly, a $17 \%$ stearate $\operatorname{diet} / 3 \%$ safflower oil diet was shown to decrease tumor size in animals injected with MDA-
MB-435 cells into the mammary fat pad [46]. When Habib et al. injected stearate into NMU treated animals, they observed a decreased number of tumors, decreased latency period until first tumor development, and decreased tumor size [47]. These studies indicate that in addition to dietary modification, it may be possible to alter fatty acid concentrations in patient through injections of individual fatty acids.

Overall animal studies support biomarker studies in that they are consistent with stearate, and n-3 fatty acids having a protective effect and oleic acid have a positive association with breast cancer risk. However in contrast to the biomarker studies, animal studies indicated that linoleate had a positive association with breast cancer risk although this may depend on the timing of breast cancer initiation and fatty acid exposure.

\section{Metastasis Studies}

In addition to affecting the development and growth of primary mammary tumors, fatty acids also have an effect on metastases. The best studied are the omega- 3 and omega- 6 fatty acids.

Linoleate has been shown to enhance breast cancer metastasis in several xenograft mouse models. This effect appears to be dose dependent, as BALB/c mice injected with the murine mammary cancer line 4526 and fed diets composed of $1,2,4$, or $8 \%$ linoleate developed $62-73 \%$ fewer lung metastases than those fed $12 \%$ linoleate $(p<0.02)$. Furthermore, as the concentration of linoleate increased in the diet, it also increased in the primary tumors [48]. Linoleate also enhances the metastasis of the MDA-MB-231 and MDA-MB-435 human breast cancer cells from the mammary fat pad to the lungs of athymic nude mice, as $21 \%$ more mice fed $12 \%$ linoleate versus $2 \%$ linoleate developed lung metastases. The reasons behind this increase are not fully understood, although linoleate increases the invasion and type IV collagenase activity of these breast cancer cells in vitro [49]. As collagen IV is a major component of the basal lamina of the basement membrane, the ability of the breast cancer cells to adhere could play a role in survival and invasion. Additionally, treatment of the animals with the highest dose of the cyclooxygenase inhibitor indomethacin suppresses linoleate induced metastasis by $42 \%$, suggesting that eicosanoids derived from linoleate may account for the increase in metastasis, perhaps through an increase in angiogenesis [50]. In support of this data, animals fed a diet of $20 \%$ safflower oil, which was enriched in linoleate had a marked increase in blood vessel areas in tumors compared to animals fed a $20 \%$ fish oil diet, which is enriched with omega 3 fatty acids $(\mathrm{p}<0.05)$ [51].

In contrast to linoleate, the omega- 3 fatty acids linolenate, eicosapentaenoic acid (EPA) and docosahexaenoic acid (DHA) have been shown to decrease metastatic tumor burden. In this study mice were maintained on an $8 \%$ linoleate diet following injection of MDA-MB-435 cells into the mammary fat pad. Seven days before excision of the primary tumor, the animals either remained on the linoleate diet or were placed on a 2, 4, or $8 \%$ EPA or DHA diet. The EPA and DHA diets successfully decreased the incidence $(p<0.02$ and 0.01 , respectively) number $(p<0.01)$ and volume of macroscopic lesions $(p<0.01)$ compared to the $8 \%$ 
linoleate diet. Interestingly, when diets were changed after primary tumor removal, the 8\% EPA and DHA diets still decreased the number of macrometastases in the lung $(\mathrm{p}<0.05$ and $\mathrm{p}<0.01$, respectively) and DHA decreased the metastatic tumor volume $(\mathrm{p}<0.05)$. [52] Feeding animals a diet composed of flaxseed oil, which was enriched in linolenate, resulted in decreased primary tumor size by $25 \%$ in the mammary fat pads of animals injected with MDAMB-435 cells and an approximately 4.5 fold decrease in the number of metastatic lesions per animal $(\mathrm{p}<0.05)$. Furthermore, the decrease in primary tumor size appeared to be due to a decrease in epidermal growth factor receptor $($ EGFR; $\mathrm{p}<0.01)$ and proliferation (as determined by Ki67 staining; $p<0.05)$. [53]. The exact reason for the decrease in metastases is unknown; however, there is some evidence that omega-3 fatty acids may inhibit angiogenesis [54].

As with the omega-3 fatty acids, dietary stearate has been shown to decrease the size of mammary fat pad tumors formed from MDA-MB-435 cells injected into the fat pads of athymic nude mice by approximately $50 \%(p<0.021$ for all other conditions tested). Additionally, stearate decreased the number of metastases to the lungs of these mice by $50 \%$ $(\mathrm{p}<0.024$ for all other conditions tested), although the effect on metastasis appears to be independent of the primary tumor size. To date the mechanism underlying this decrease is unclear, although it may involve the induction of apoptosis in the cancer cells [46].

Dietary fatty acids influence breast cancer metastasis in animal models. Dietary n-3 fatty acids and stearate appear to decrease metastatic tumor burden while linoleate promotes metastasis numbers and incidence.

\section{FATTY ACIDS AND CANCER CELLS IN VITRO}

The major fatty acids found in the human plasma, and those well studied with breast cancer are profiled. These include palmitate, stearate, oleate, linoleate, arachidonate, linolenate, EPA and DHA. See Table 1 for a summary of the characteristics of each fatty acid. Approximate serum concentrations of individual fatty acids are based on a measured average fasting total non-esterified fatty acids of $750 \mu \mathrm{M}$, as well as the percentage of each in the US population, and are provided to give perspective to the concentrations of individual fatty acids used for in vitro studies $[7,8]$.

\section{Palmitate}

Palmitate is the most abundant non-esterified or free saturated fatty acid in human serum at a fasting concentration of $\sim 165 \mu \mathrm{M}$ and is also the most abundant saturated fatty acid in the diet. Palmitate can either be supplied exogenously or endogenously through activation of fatty acid synthase (FAS). When supplied exogenously, treatment of breast cancer cells with $150 \mu \mathrm{M}$ palmitate inhibited epidermal growth factor (EGF)-induced proliferation by approximately $45 \%$ [55]. Furthermore, 100 $\mu \mathrm{M}$ palmitate for 24 hours inhibits breast cancer cell growth by approximately $90 \%$ and treatment with bromo-palmitate did not affect cell growth indicating that palmitate must be metabolized to inhibit growth [56, 57]. The mechanisms underlying palmitate-induced breast cancer cell death are unknown although $100 \mu \mathrm{M}$ palmitate decreased mitochondrial membrane potential, increased cytochrome $\mathrm{C}$ concentrations in the cytosol, and activated caspase- 3 in a time dependent manner [57]. This suggests palmitate is inducing apoptosis through the intrinsic apoptotic cascade. Palmitate decreased the levels of cardiolipin, the phospholipid that sequesters cytochrome $\mathrm{C}$ in the mitochondria, indicating that palmitate can act directly on the mitochondria to induce apoptosis [57].

Inhibition of acetyl-CoA carboxylase $\alpha(\mathrm{ACC} \alpha)$ and inhibition of FAS with siRNA resulted in decreased synthesis of palmitate and induced apoptosis of human breast cancer cells. When the cells lacking FAS or ACC $\alpha$ were treated with $100 \mu \mathrm{M}$ palmitate, the decrease in cell viability was reversed by approximately $94 \%$, once again stressing the importance of fatty acids, and in this instance, palmitate, on breast cancer survival [58].

\section{Stearate}

Stearate is the second most abundant circulating nonesterified saturated fatty acid in fasting human serum at $\sim 53$ $\mu \mathrm{M}$. However, little research has been done investigating the effect of this fatty acid on breast cancer development and progression. $150 \mu \mathrm{M}$ stearate has been shown to inhibit EGF-induced Hs578t breast cancer cell proliferation by approximately $95 \%$ [55]. Furthermore, $10-25 \mu \mathrm{M}$ stearate is known to induce translocation of Annexin II to detergent resistant membrane in the $\mathrm{Hs} 578 \mathrm{t}$ cells, hypothetically affecting cellular signaling through modifications of lipid rafts and protein acylation, although the effect on the cancer cell phenotype is not known [59]. As with palmitate, 25-150 $\mu \mathrm{M}$ stearate has been shown to preferentially inhibit growth and induce apoptosis of breast cancer cells, potentially through the induction of de novo diacyglycerol synthesis and activation of protein kinase $C$ [46, 57, 60, 61]. Interestingly, the apoptotic effect of stearate appears to be cancer cell specific as treatment of non-transformed breast cells has no effect on cell survival $[60,61]$.

\section{Oleate}

Oleate is present in fasting serum at a concentration of $\sim 180 \mu \mathrm{M}$. In animal studies, the effect of oleate has been either a slight increase in tumor formation or no effect. However, epidemiological data from people on the so called high-olive oil Mediterranean diet, indicate they experience a decrease in breast cancer rates [62]. Because oleate is found in high concentrations in olive oil, it is hypothesized to be the major constituent associated with the results in the epidemiological studies. The effect of oleate on breast cancer cells in vitro, however, tells a story that is more closely related to the animal studies.

In 1990 Rose and Connolly found they could promote the growth of breast cancer cells with very low concentrations $(0.9 \mu \mathrm{M})$ of oleate whereas higher concentrations (3.5-8.9 $\mu \mathrm{M})$ inhibited growth [56]. When cells were treated with the chemotherapeutic doxorubicin, an oxidizing agent, and DHA, cell viability was greatly decreased, below that of doxorubicin alone. However, when cells were treated with oleate instead of DHA, the viability of the cancer cells was equivalent to doxorubicin, indicating oleate does not appear to have chemotherapeutic properties [63]. 
Extended survival studies have shown that oleate extends the lifespan of serum starved cells. The untreated cells began to die within 24 hours and were completely dead by day 6 . On the other hand, 33-400 $\mu \mathrm{M}$ oleate had a protective effect and $100 \mu \mathrm{M}$ decreases the caspase- 3 activity induced by serum starving, thereby promoting survival. When a panel of breast cell lines was tested, $100 \mu \mathrm{M}$ oleate promoted survival of the T-47D and MDA-MB-468 breast cancer cells in addition to MDA-MB-231 cells by approximately $1.5,1.6$, and 12.7 fold, respectively [64]. Interestingly no effect was observed in the MCF-7 breast cancer cells or the MCF-10A non-cancerous breast epithelial cells [64].

Hardy et al. demonstrated that $250-500 \mu \mathrm{M}$ oleate increased proliferation of the MDA-MB-231, ZR-75-1, and MCF-7 breast cancer cells but not the T-47D by 1.6 to 6.5 fold as determined by tritated thymidine uptake. Oleate also reversed palmitate-induced apoptosis in the MDA-MB-231 and $\mathrm{T}-47 \mathrm{D}$ cells. The ability of oleate to prevent palmitate induced apoptosis and promote survival appears to be due to the activation of phosphatidylinositol-3-kinase (PI3K) [57]. The reasons for the different responses between the cell lines in terms of survival studies and the proliferation study are unknown but may be due, at least in part, to differences in cell culture lines between laboratories.

As mentioned previously fatty acid synthase is crucial for breast cancer cell survival and inhibition of the FAS complex results in cell death. One of the common ways to inhibit FAS is to use the pharmacologic inhibitor cerulenin. Cerulenin decreased the viability of the SK-Br3 cells; however, when breast cancer cells were treated with oleate in addition to cerulenin, a decrease in cell toxicity was observed [65]. Once again, these results suggest oleate promotes cell survival [65].

In addition to affecting proliferation and survival, oleate has been shown recently to promote cell migration. Treatment of MDA-MB-231 breast cancer cells with 100$400 \mu \mathrm{M}$ oleate promotes cell migration by approximately 2 4.7 fold. Further molecular experiments revealed this migration was induced by oleate-mediated production of arachidonate, which in turn activated focal adhesion kinase (FAK) [66]. Furthermore, $500 \mu \mathrm{M}$ oleate induced invasion of MDA-MB-231 cells through Matrigel by approximately 2 fold [67].

If oleate is associated with an increase in breast cancer cell survival, migration and invasion, why do people on the Mediterranean diet have a decreased risk for breast cancer? In addition to being rich in oleate, olive oil is also enriched with phenols that have been shown to have anti-cancer properties and therefore, the effects of olive oil may not be due to oleate [68]. This points out one of the primary problems with dietary studies using oils - they contain many compounds besides fatty acids that may be carcinogenic or anti-carcinogenic. In addition the Mediterranean diet also includes fish, a rich source of n-3 fatty acids, which also have anti-cancer properties.

\section{Linoleate}

The fasting serum concentration of linoleate is $\sim 195 \mu \mathrm{M}$. Many in vivo studies have been performed with corn oil and safflower oil, two oils enriched in linoleate that show a tumor promoting effect. Consistent with the animal data, in vitro experiments indicate $17.8 \mathrm{nM}-2.7 \mu \mathrm{M}$ linoleate can stimulate proliferation of breast cancer cells by approximately 1.5-5.2 fold in a dose dependent manner [69]. Treatment with the cyclooxygenase and 5-lipooxygenase inhibitor indomethacin reversed the pro-proliferation effect of $2.2 \mu \mathrm{M}$ linoleate [56]. Treatment with the cyclooxygenase inhibitor piroxicam had no effect on linoleate-induced proliferation whereas the 5-lipooxygeanse inhibitors esculetin and nordihydroguaiaretic acid (NDGA) reversed the effect similar to indomethacin. These results suggest that the leukotrienes produced by 5-lipooxygenase and not the prostaglandins produced by cyclooxygenase are important in linoleate-induced proliferation and survival [56]. Consistent with this hypothesis linoleate was found to induce proliferation, activate phospholipase $\mathrm{C}$, and protein kinase $\mathrm{C}$ with no effect on prostaglandin E2 (PGE2) secretion indicating that cyclooxygenase activity was not involved [70].

Treatment with linoleate increased the number of cells in S-phase. Furthermore, microarray data indicated that linoleate could modulate expression of various proteins involved in cell cycle regulation and cell growth. For example, linoleate induced expression of the estrogen receptor which is known to be a growth stimulant when activated. On the other hand, linoleate decreased androgen receptor expression which is known to antagonize the effects of the estrogen receptor [71].

The effects of linoleate are not just specific to breast cancer cells. Epithelial cells isolated from normal breast tissue showed maximal growth stimulation when cultured with insulin, EGF and linoleate. This growth could be inhibited with indomethacin and the inhibition could be reversed with the addition of PGE2. Interestingly, epithelial cells isolated from fibroadenomas were unresponsive to linoleate. The normal epithelial cells showed an increase of linoleate being shuttled into the arachidonate pathway to increase prostaglandin expression compared to the fibroadenoma epithelial cells [72]. Unlike Rose's work with the breast cancer cell lines, these results indicate prostaglandins may play a role in at least some of the effects seen with linoleate.

Linoleate does not only affect proliferation, it can also stimulate breast cancer cell invasion. Treatment of the MDAMB-435 breast cancer cells with $0.89 \mu \mathrm{M}$ and $1.7 \mu \mathrm{M}$ linoleate resulted in an increase in cell invasion through Matrigel of approximately $35 \%$ and $55 \%$, respectively, and an increase in type IV collagenase activity compared to untreated cells and these effects were inhibited by indomethacin $[73,74]$. These results indicate that either prostaglandins or leukotrienes may be involved in linoleateinduced invasion. Additionally, $500 \mu \mathrm{M}$ of linoleate was sufficient to induce a 4 fold increase in cell invasion via a PAI1 dependent mechanism [67].

\section{Arachidonate}

Arachidonate is present in fasting serum at approximately the same concentration as stearate, $\sim 60 \mu \mathrm{M}$. When linoleate enters into a cell, it is converted to arachidonate through a three step process. Arachidonate is then converted to eicosanoids, including the 2-series prostanoids, prostaglandins and thromboxanes, lipoxins, and the 4-series 
leukotrienes. As mentioned above, inhibition of 5lipooxygenase results in an inhibition of leukotriene formation, whereas inhibition of cyclooxygenase causes a decrease in prostaglandins and thromoxanes [14]. Since linoleate can be converted to arachidonate, much of the work studying arachidonate does so by studying its metabolism. However, this section, similar to previous sections on other fatty acids, will focus on the effects of arachidonate applied exogenously to breast cancer cells.

One of the most striking features of treatment of the MDA-MB-435 cells with $30 \mu \mathrm{M}$ arachidonate is an increase in cell adhesion to type IV collagen by approximately 1.7 fold. A large amount of work has been done investigating this adhesion phenomenon. Arachidonate induced activation of the MAP kinase p38. Activation of this enzyme was confirmed by phosphorylation of its downstream target MAP kinase-activated protein kinase 2 (MAPKAPK2). The activation of p38 was dependent on the dose of arachidonate and inhibition of p38 reversed arachidonate-induced cell adhesion [75]. Arachidonate-mediated cell adhesion was also dependent on the activation of PKC $\mu$. Following activation, PKC $\mu$ was cleaved by calpain. When this cleavage was inhibited, the cells did not adhere to collagen IV. Interestingly, inhibition of p38 did not prevent PKC $\mu$ phosphorylation and vice versa. However, inhibition of p38 did partially prevent $\mathrm{PKC} \mu$ cleavage by calpain [76].

When arachidonate enters the cell, it is converted to 15(S)-hydroxyeicosatetraenoic acid (15(S)-HETE) by 15 lipooxygenase. When 15(S)-HETE was added directly to MDA-MB-435 cancer cells, it stimulated breast cancer cell adhesion in a dose dependent manner. Furthermore, treatment with 15(S)-HETE stimulated phosphorylation of $\mathrm{p} 38$, indicating that it is the major eicosanoid responsible for arachidonate mediated adhesion [77].

Adhesion and migration involve the rearrangement of focal adhesion, induced by the activation of FAK. Treatment with $15 \mu \mathrm{M}$ arachidonate for 48 hours significantly increased migration of the MDA-MB-231 cells by approximately 4 fold and treatment for 10-20 minutes significantly activated FAK in the MDA-MB-231, MCF-7, and ZR-75 cells. No effect was observed in the MCF-10A breast epithelial cells. The activation of FAK could be prevented by pretreatment with the antioxidant nordihydroguaiaretic acid (NDGA) indicating a lipooxygenase product was responsible for FAK activation. In addition to activating FAK, arachidonate also activated src in the MDA-MB-231, MCF-7 and ZR-75 cells. Finally, inhibition of the lipooxygenases or src prevented the increase in migration due to arachidonate [66].

In addition to affecting adhesion and migration, arachidonate has also been implicated in cell proliferation. Treatment of T-47D breast cancer cells with $8.2 \mu \mathrm{M}$ arachidonate stimulated growth and induced expression of cyclin D1 which has previously been associated with an increase in cell proliferation [78]. On the other hand treatment of MDA-MB-231 and MCF-7 cells with 1-50 $\mu \mathrm{M}$ causes decreased cell viability in a dose dependent manner. In the MDA-MB-231 cells, this decrease was associated with the activation of caspase- 9 and caspase- 3 indicating the decrease in viability is due to activation of the intrinsic apoptotic cascade [79].

\section{Linolenate}

The concentration of linolenate in fasting serum is $\sim 5 \mu \mathrm{M}$. The effects of the essential omega- 3 fatty acid alphalinolenate on breast cancer cells have not been well studied and characterized with in vitro models. Relatively few studies treated cells with linolenate - the majority of studies looking at the omega-3 fatty acids use DHA or EPA and these studies are discussed in the next section. Overall, however, linolenate appears to specifically inhibit breast cancer cell growth. Treatment of the MCF-7 cells with 6-30 $\mu \mathrm{M}$ linolenate shows a dose dependent decrease in cell proliferation. Treatment of MCF-10A cells with 6-30 $\mu \mathrm{M}$ linolenate had largely no effect, although a decrease in viability was observed at the highest concentration. The effect was observed whether linolenate was supplied as a free fatty acid bound to albumin, or as a phospholipid enriched lysosome [80]. 25-100 $\mu \mathrm{M}$ linolenate also decreased the proliferation of the MDA-MB-231 breast cancer cells in a dose dependent manner [81]. Furthermore, treatment of MCF-7 cells with 75 and $100 \mu \mathrm{M}$ linolenate for 48 hours increased the number of apoptotic cells by 18 and $16 \%$, respectively [82].

\section{Docosahexaenoic Acid (DHA) and Eicosapentaenoic Acid (EPA)}

The concentrations of DHA and EPA in fasting serum are $13 \mu \mathrm{M}$ and $6 \mu \mathrm{M}$ respectively. DHA and EPA are generally referred to as the omega-3 fish oils as they are found in high concentration in oily fish such as salmon. When linolenate enters into a cell, it is converted to EPA through the same pathway that converts linoleate to arachidonate. EPA can also be converted to DHA and vice versa. EPA is the precursor to the 3 -series prostanoids, prostaglandins and thromboxanes, lipoxins, and the 5-series leukotrienes. Interestingly, these eicosanoids generally have the opposite effect as those derived from arachidonate, meaning they are generally anti-inflammatory and anti-carcinogenic [14].

DHA and EPA have been shown to inhibit the growth of several different breast cancer cell lines at different concentrations. $100 \mu \mathrm{M}$ EPA and DHA have been shown to decrease cell growth after 5 days treatment. In addition, there was a dose $(1-100 \mu \mathrm{M})$ dependent inhibition of colony growth [83]. In another study, 40-160 $\mu \mathrm{M}$ DHA was found to inhibit MCF-7 growth in a dose dependent manner. A time dependent increase in apoptosis was observed 24, 48, and 72 hours post-treatment. Consistent with this finding, the Bax/Bcl-2 ratio increased 48 to 72 hours after treatment indicating a possible mechanism for the induction of apoptosis [84]. DHA $(25 \mu \mathrm{M})$ also induced apoptosis in MDA-MB-231 cells through a mechanism dependent on ceramide formation [85].

Multiple other mechanisms have been linked to the apoptotic effect of DHA. Treatment of MDA-MB-231 cells with $50 \mu \mathrm{M}$ DHA caused an increase in the PPAR $\gamma$ expression and a subsequent decrease in NFKB activity. No effect was observed with EPA [86]. Furthermore, $30 \mu \mathrm{M}$ DHA has been shown to activate PPAR $\gamma$ and induce caspase3 activity in MCF-7 cells. Once again, no effect was seen with EPA, indicating it does not play a role in activating PPAR $\gamma[87]$. 
In addition to affecting proliferation and survival, DHA has also been shown to sensitize MCF-7 and MDA-MB-231 cells when used with the chemotherapeutic agent doxorubicin $[63,88]$. To date, the mechanisms underlying these effects are largely unknown.

\section{SUMMARY}

In some ways, the in vitro data can be as difficult to interpret as the animal and epidemiological studies. Different results are observed in the same cell lines, concentrations are inconsistent, and in many cases, not physiological. The majority of the studies focus on one fatty acid, while in vivo multiple fatty acids are present. It will be important to verify the molecular mechanisms proposed from in vitro studies in vivo. Yet, despite these inconsistencies and unconfirmed mechanisms, many of the in vitro studies show results similar to the animal studies.

When breast cancer cells were treated with exogenous palmitate, the cells underwent apoptosis [57]. However, if FAS expression was decreased by siRNA and the cells were treated with palmitate, it increased survival [58]. Therefore, depending on FAS expression, palmitate can either induce or inhibit cytotoxicity. Stearate, on the other hand, shows consistent anti-cancer properties, including the inhibition of proliferation and induction of apoptosis. The omega- 6 fatty acids linoleate and arachidonate appear to promote carcinogenesis by promoting both growth and invasion of cancer cells. Finally, the omega-3 fatty acids such as linolenate, DHA and EPA inhibit carcinogenesis by decreasing cell viability, proliferation, invasion, and increasing chemosensitivity.

\section{DISCUSSION}

Despite hundreds of epidemiological, in vivo, and in vitro studies investigating the role of fatty acids on breast cancer, a definitive conclusion on fatty acids as a group remains elusive. Clearly the timing of dietary fat exposure is important as are the differences in metabolism and synthesis of fatty acids between individuals. Nevertheless the above epidemiological, biomarker, animal and cellular studies indicate that it is likely to be important to find the right balance of individual dietary fatty acids rather than groups of fatty acids such as saturated and unsaturated fatty acids.

Specifically, it is difficult to ignore the breast cancer promoting effects of linoleate and palmitate and the inhibiting effect of stearate, EPA and DHA. While increasing dietary EPA and DHA are reasonably well accepted as being beneficial to human health, increasing dietary stearate, a long chain saturated fatty acid, may seem like a risky proposition. However human studies indicate that dietary stearate lowers total cholesterol and low density lipoprotein cholesterol or so called "bad cholesterol" (LDLc) [89]. Also stearate is slowly metabolized and is preferentially incorporated into membrane phospholipids $[90,91]$. In addition, other human studies indicate that increasing dietary stearate does not increase thrombosis or insulin resistance [92-94]. Furthermore, serum concentrations of stearate are approximately doubled in the Hong Kong population, which also has increased levels of EPA and DHA as well as reduced palmitate compared to the US population. In addition, women in Hong Kong have a lifetime risk of breast cancer that is approximately half that of US women [95]. While the reasons for the reduced risk of breast cancer are likely to be complex and multifactorial these studies in total point to the possibility of raising serum concentrations of stearate, EPA and DHA.

The Dietary Guidelines for Americans recommends the majority of dietary fats be composed of omega-3 and omega6 fatty acids (polyunsaturated fatty acids) and oleate (monounsaturated fatty acid) with limited intake of saturated fatty acids [96]. Fig. (4) depicts the current balance of fatty acid dietary recommendations as well as a potential neutral balance of individual fatty acids for breast cancer progression. We live in a fat-phobic society, especially in terms of saturated fatty acids. But as we decrease the intake of saturated fatty acids, we increase the consumption of other fatty acids and or carbohydrates which may promote breast cancer development and progression.

The relationship between dietary fat and breast cancer is a very complex one, confounded by many issues and caveats. So while it is worth noting that the current dietary guidelines may be inappropriate in terms of breast health, one cannot ignore the contributions of other factors to this issue, including the production of endogenous fatty acids, timing of dietary fat exposure, and caloric restriction. While an in depth discussion of each of these subjects is beyond the scope of this review, we highlight key points as follows.

Endogenous production of fatty acids: As described previously, FAS is responsible for the production of saturated fatty acids that can then be converted to other fatty acids, with the exception of the essential fatty acids. In 1994, an overexpressed, poor prognostic breast cancer marker was isolated, sequenced and identified as FAS [11]. FAS has since been found to be associated with a decrease in both disease free survival and overall survival [97]. For reasons that are not completely understood, it is thought that cancer cells require de novo synthesis of fatty acids, possibly for the generation of phospholipids and $2^{\text {nd }}$ messengers mentioned previously [11]. In addition to being an indicator of poor prognosis, many studies have been performed showing inhibition of FAS leads to death of cancer cells, indicating it may be a potential chemotherapeutic target [98]. To date, the differences between metabolism of endogenously produced fatty acids and those acquired from the diet are unknown.

Timing of Dietary Fat Exposure: Population based studies suggest that dietary fat has an effect on the risk for breast cancer depending on where the studies were performed. For example Asian American women are at low risk of breast cancer when born in Asia; however, Asian American women who are born in America are at higher risk which is comparable to that of American women. The delay of increased risk for breast cancer for a generation suggests the possibility of diet during pregnancy as an important factor. Clarke et al. have suggested that a high fat diet during pregnancy may increase breast cancer risk in response to carcinogen exposure later in life [99]. Specifically, they hypothesize that a high fat diet increases estrogen in utero which leads to reduced epithelial differentiation, reduced protein kinase $\mathrm{C}$ activity, and reduced estrogen receptors in the developing mammary gland which leads to increased susceptibility to transformation and an increased incidence of breast cancer in response to chemical carcinogens. Clarke 


\section{Current ADA Dietary Fat Intakes}

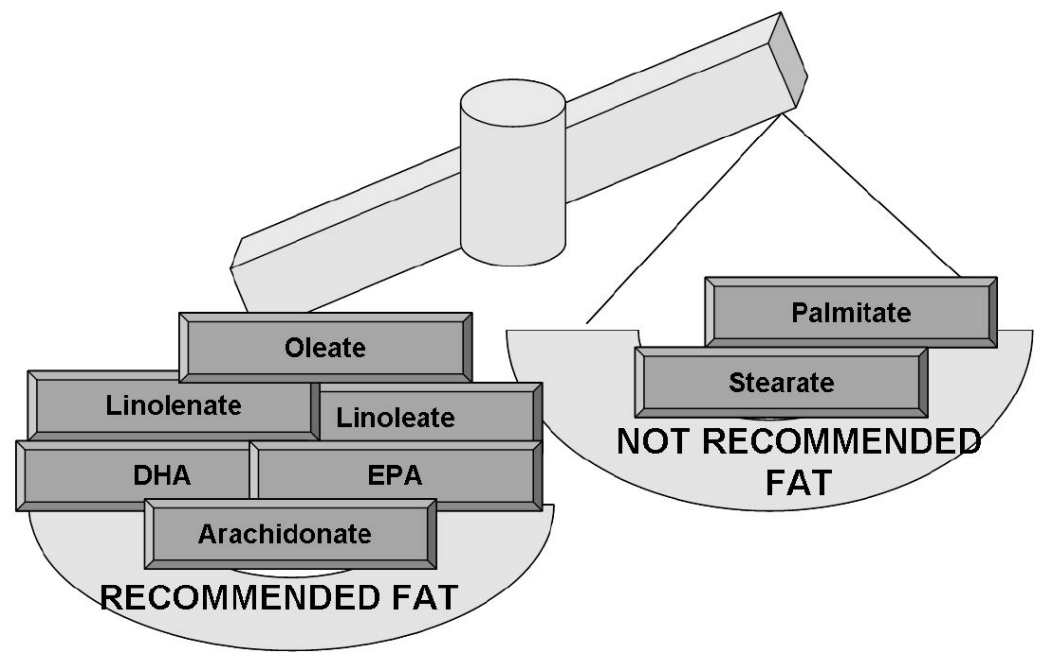

\section{Effect of Individual Fatty Acids on Breast Cancer}

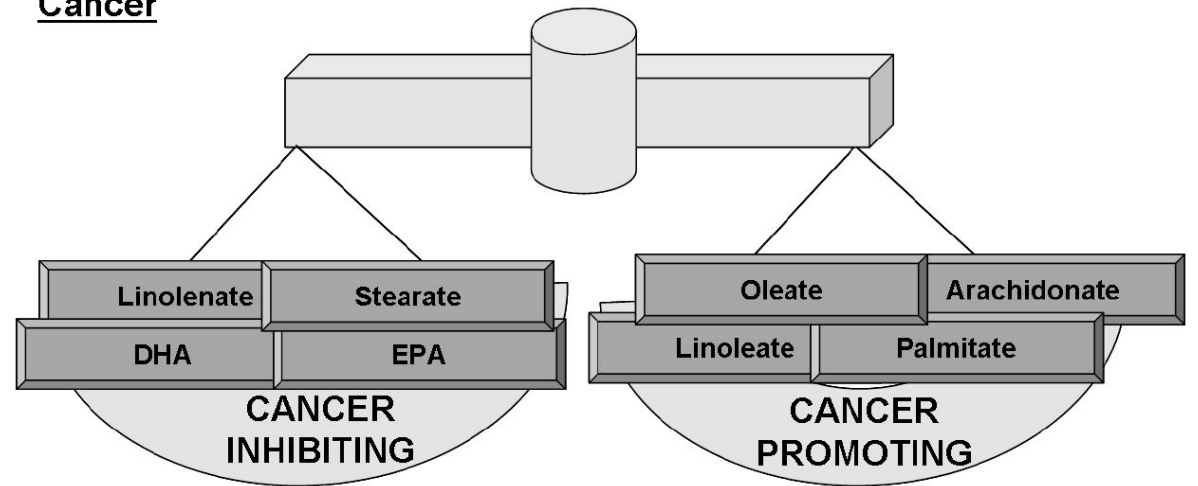

Fig. (4). Balancing dietary fatty acids with respect to breast cancer risk: A current view of ADA recommended dietary fatty acids and the effect of individual fatty acids on breast cancer progression based on in vitro, in vivo and human dietary fat biomarker studies. Note that we are not recommending eliminating any of the fatty acids listed above but rather put forward the notion of shifting proportions of individual fatty acids to minimize breast cancer risk.

also points out that since $\sim 60 \%$ of breast tumors are ER+ and a high fat diet may affect only this group of patients (indirect evidence) the power of cohort studies to detect an effect of a high fat diet on breast cancer risk may be adversely affected since a significant amount of breast tumors are ER- [99].

Caloric Restriction: There is little doubt that total caloric intake is related to increased risk of breast cancer in animal models. In some cases a dramatic effect has been demonstrated. For example Boissonneault et al. have shown a $30 \%$ calorie reduction resulted in a $90 \%$ reduction in mammary cancer [100]. However in humans this is complicated by the relationship of caloric intake to physical exercise [101]. Caloric intake increases with physical exercise, which has a beneficial effect on cardiovascular disease [102]. The relationship of an excess caloric intake compared to output has opposite effects on women's risk for breast cancer depending on menopausal status. Premenopausal women with excess calories have a reduced incidence of breast cancer while postmenopausal women have increased risk. These differences are likely to be related to estrogen levels. It has been proposed that the decreased risk in premenopausal women may be due to a lack of ovulation in some obese women while the increased risk in postmenopausal women may be due to increased conversion of androgens to estrogens [103-106].

\section{CONCLUSIONS}

Recognizing that not all dietary saturated fatty acids have negative effects on breast cancer while not all unsaturated fatty acids have positive effects is an important conceptual step to finding the "neutral" or optimal balance of individual dietary fatty acids for breast cancer risk. To obtain the optimal balance of dietary fatty acids for minimizing breast cancer risk it will be important to understand the mechanism of action of how individual fatty acids affect the various stages of cancer, from initiation and tumor growth to metastasis. 


\section{SOURCES OF SUPPORT}

NIH Grant Number R21 AT 001636 (RWH) from the National Center for Complementary and Alternative Medicine (NCCAM). Its contents are solely the responsibility of the authors and do not necessarily represents of the official views of the NCCAM, or the National Institutes of Health. Funding was also provided by the National Cattlemen's Beef Association (LME, predoctoral fellowship/RWH) and the University of Alabama Breast Cancer Spore Program.

\section{REFERENCES}

[1] Doll R, Peto R. The causes of cancer: quantitative estimates of avoidable risks of cancer in the United States today. J Natl Cancer Inst 1981; 66(6): 1191-308.

[2] Tannenbaum A. The genesis and growth of tumors III. effects of a high fat diet. Cancer Res 1942; 2(7): 468-75.

[3] Carroll KK. Experimental evidence of dietary factors and hormonedependent cancers. Cancer Res 1975; 35(11 Pt. 2): 3374-83.

[4] Voet DaV JG. Biochemistry, $3^{\text {rd }}$ ed. Hoboken, NJ: John Wiley \& Sons, Inc 2000; pp. 382-4.

[5] Thompson AK, Shaw DI, Minihane AM, Williams CM. Trans-fatty acids and cancer: the evidence reviewed. Nutr Res Rev 2008; 21(2): 174-88

[6] Berg JM, Tymoczko JL, Stryer L. Biochemistry. $5^{\text {th }}$ ed. New York, NY: W.H. Freeman and Company 2001; p. 601.

[7] Banini AE, Allen JC, Allen HG, Boyd LC, Lartey A. Fatty acids, diet, and body indices of type II diabetic American whites and blacks and Ghanaians. Nutrition 2003; 19(9): 722-6.

[8] Lee HY, Woo J, Chen ZY, Leung SF, Peng XH. Serum fatty acid, lipid profile and dietary intake of Hong Kong Chinese omnivores and vegetarians. Eur J Clin Nutr 2000; 54(10): 768-73.

[9] Mougios V, Ring S, Petridou A, Nikolaidis MG. Duration of coffee- and exercise-induced changes in the fatty acid profile of human serum. J Appl Physiol 2003; 94(2): 476-84.

[10] Voet DaV JG. Biochemistry, $3^{\text {rd }}$ ed. Hoboken, NJ: John Wiley \& Sons, Inc 2000; pp. 930-4.

[11] Kuhajda FP, Jenner K, Wood FD, et al. Fatty acid synthesis: a potential selective target for antineoplastic therapy. Proc Natl Acad Sci USA 1994; 91(14): 6379-83.

[12] Voet DaV JG. Biochemistry, $3^{\text {rd }}$ ed. Hoboken, NJ: John Wiley \& Sons, Inc 2000; pp. 915-6.

[13] Voet DaV JG. Biochemistry, $3^{\text {rd }}$ ed. Hoboken, NJ: John Wiley \& Sons, Inc 2000; p. 915.

[14] Larsson SC, Kumlin M, Ingelman-Sundberg M, Wolk A. Dietary long-chain $\mathrm{n}-3$ fatty acids for the prevention of cancer: a review of potential mechanisms. Am J Clin Nutr 2004; 79(6): 935-45.

[15] Kris-Etherton PM, Innis S, Ammerican Dietetic A, Dietitians of C. Position of the American Dietetic Association and Dietitians of Canada: dietary fatty acids. J Am Diet Assoc 2007; 107(9): 15991611.

[16] Simopoulos AP. Human requirement for N-3 polyunsaturated fatty acids. Poult Sci 2000; 79(7): 961-70.

[17] Lands WE. Dietary fat and health: the evidence and the politics of prevention: careful use of dietary fats can improve life and prevent disease. Ann N Y Acad Sci 2005; 1055: 179-92.

[18] Simopoulos AP, Leaf A, Salem N, Jr. Workshop statement on the essentiality of and recommended dietary intakes for Omega-6 and Omega-3 fatty acids. Prostaglandins Leukot Essent Fatty Acids 2000; 63(3): 119-21.

[19] Byers T. Nutritional risk factors for breast cancer. Cancer 1994; 74(1 Suppl): 288-95.

[20] Hunter DJ, Spiegelman D, Adami HO, et al. Cohort studies of fat intake and the risk of breast cancer--a pooled analysis. N Engl J Med 1996; 334(6): 356-61.

[21] Howe GR, Hirohata T, Hislop TG, et al. Dietary factors and risk of breast cancer: combined analysis of 12 case-control studies. J Natl Cancer Inst 1990; 82(7): 561-9.

[22] Boyd NF, Stone J, Vogt KN, Connelly BS, Martin LJ, Minkin S. Dietary fat and breast cancer risk revisited: a meta-analysis of the published literature. Br J Cancer 2003; 89(9): 1672-85.

[23] Sieri S, Krogh V, Ferrari P, et al. Dietary fat and breast cancer risk in the European Prospective Investigation into Cancer and Nutrition. Am J Clin Nutr 2008; 88(5): 1304-12.
[24] Engeset D, Alsaker E, Lund E, et al. Fish consumption and breast cancer risk. The European Prospective Investigation into Cancer and Nutrition (EPIC). Int J Cancer 2006; 119(1): 175-82.

[25] Gonzalez CA. The European Prospective Investigation into Cancer and Nutrition (EPIC). Public Health Nutr 2006; 9(1A): 124-6.

[26] Schulz M, Hoffmann K, Weikert C, Nothlings U, Schulze MB, Boeing $\mathrm{H}$. Identification of a dietary pattern characterized by highfat food choices associated with increased risk of breast cancer: the European Prospective Investigation into Cancer and Nutrition (EPIC)-Potsdam Study. Br J Nutr 2008; 100(5): 942-6.

[27] Prentice RL, Anderson GL. The women's health initiative: lessons learned. Annu Rev Public Health 2008; 29: 131-50.

[28] Prentice RL, Caan B, Chlebowski RT, et al. Low-fat dietary pattern and risk of invasive breast cancer: the Women's Health Initiative Randomized Controlled Dietary Modification Trial. JAMA 2006; 295(6): 629-42.

[29] Thacker HL. A low-fat dietary pattern intervention did not reduce incidence of breast cancer, colorectal cancer, or CVD in postmenopausal women. ACP J Club 2006; 145(1): 6-7.

[30] Prentice RL, Thomson CA, Caan B, et al. Low-fat dietary pattern and cancer incidence in the Women's Health Initiative Dietary Modification Randomized Controlled Trial. J Natl Cancer Inst 2007; 99(20): 1534-43.

[31] Yngve A, Hambraeus L, Lissner L, et al. The Women's Health Initiative. What is on trial: nutrition and chronic disease? Or misinterpreted science, media havoc and the sound of silence from peers? Public Health Nutr 2006; 9(2): 269-72.

[32] Copeland T, Grosvenor M, Mitchell DC, et al. Designing a quality assurance system for dietary data in a multicenter clinical trial Women's Intervention Nutrition Study. J Am Diet Assoc 2000; 100(10): 1186-90.

[33] Chlebowski RT, Rose D, Buzzard IM, et al. Adjuvant dietary fat intake reduction in postmenopausal breast cancer patient management. The Women's Intervention Nutrition Study (WINS). Breast Cancer Res Treat 1992; 20(2): 73-84.

[34] Blackburn GL, Wollner S, Heymsfield SB. Lifestyle interventions for the treatment of class III obesity: a primary target for nutrition medicine in the obesity epidemic. Am J Clin Nutr 2010; 91(1): 289S-92S.

[35] Chlebowski RT, Blackburn GL, Thomson CA, et al. Dietary fat reduction and breast cancer outcome: interim efficacy results from the Women's Intervention Nutrition Study. J Natl Cancer Inst 2006; 98(24): 1767-76.

[36] Blackburn GL, Wang KA. Dietary fat reduction and breast cancer outcome: results from the Women's Intervention Nutrition Study (WINS). Am J Clin Nutr 2007; 86(3): S878-81.

[37] Pierce JP, Natarajan L, Caan BJ, et al. Influence of a diet very high in vegetables, fruit, and fiber and low in fat on prognosis following treatment for breast cancer: the Women's Healthy Eating and Living (WHEL) randomized trial. JAMA 2007; 298(3): 289-98.

[38] Lee MM, Lin SS. Dietary fat and breast cancer. Annu Rev Nutr 2000; 20: 221-48.

[39] Saadatian-Elahi M, Norat T, Goudable J, Riboli E. Biomarkers of dietary fatty acid intake and the risk of breast cancer: a metaanalysis. Int J Cancer 2004; 111(4): 584-91.

[40] Shannon J, King IB, Moshofsky R, et al. Erythrocyte fatty acids and breast cancer risk: a case-control study in Shanghai, China. Am J Clin Nutr 2007; 85(4): 1090-7.

[41] Welsch CW. Relationship between dietary fat and experimental mammary tumorigenesis: a review and critique. Cancer Res 1992; 52(7 Suppl): 2040s-8s

[42] Thompson HJ, Meeker LD, Tagliaferro AR, Roberts JS. Effect of energy intake on the promotion of mammary carcinogenesis by dietary fat. Nutr Cancer 1985; 7(1-2): 37-41.

[43] Tinsley IJ, Schmitz JA, Pierce DA. Influence of dietary fatty acids on the incidence of mammary tumors in the $\mathrm{C} 3 \mathrm{H}$ mouse. Cancer Res 1981; 41(4): 1460-5.

[44] Hopkins GJ, West CE, Hard GC. Effect of dietary fats on the incidence of 7,12-dimethylbenz(a)-anthracene-induced tumors in rats. Lipids 1976; 11(4): 328-33.

[45] Bennett AS. Effect of dietary stearic acid on the genesis of spontaneous mammary adenocarcinomas in strain A/ST mice. Int J Cancer 1984; 34(4): 529-33.

[46] Evans LM, Toline EC, Desmond R, Siegal GP, Hashim AI, Hardy RW. Dietary stearate reduces human breast cancer metastasis 
burden in athymic nude mice. Clin Exp Metastasis 2009; 26(5):415-24.

[47] Habib NA, Wood CB, Apostolov K, et al. Stearic acid and carcinogenesis. Br J Cancer 1987; 56(4): 455-8.

[48] Hubbard NE, Erickson KL. Enhancement of metastasis from a transplantable mouse mammary tumor by dietary linoleic acid. Cancer Res 1987; 47(23): 6171-5.

[49] Rose DP, Connolly JM, Liu XH. Effects of linoleic acid on the growth and metastasis of two human breast cancer cell lines in nude mice and the invasive capacity of these cell lines in vitro. Cancer Res 1994; 54(24): 6557-62.

[50] Connolly JM, Liu XH, Rose DP. Dietary linoleic acid-stimulated human breast cancer cell growth and metastasis in nude mice and their suppression by indomethacin, a cyclooxygenase inhibitor. Nutr Cancer 1996; 25(3): 231-40.

[51] Mukutmoni-Norris M, Hubbard NE, Erickson KL. Modulation of murine mammary tumor vasculature by dietary $n-3$ fatty acids in fish oil. Cancer Lett 2000; 150(1): 101-9.

[52] Rose DP, Connolly JM, Coleman M. Effect of omega-3 fatty acids on the progression of metastases after the surgical excision of human breast cancer cell solid tumors growing in nude mice. Clin Cancer Res 1996; 2(10): 1751-6.

[53] Chen J, Stavro PM, Thompson LU. Dietary flaxseed inhibits human breast cancer growth and metastasis and downregulates expression of insulin-like growth factor and epidermal growth factor receptor. Nutr Cancer 2002; 43(2): 187-92.

[54] Hardman WE, Sun L, Short N, Cameron IL. Dietary omega-3 fatty acids and ionizing irradiation on human breast cancer xenograft growth and angiogenesis. Cancer Cell Int 2005; 5(1): 12.

[55] Wickramasinghe NS, Jo H, McDonald JM, Hardy RW. Stearate inhibition of breast cancer cell proliferation. A mechanism involving epidermal growth factor receptor and G-proteins. Am J Pathol 1996; 148(3): 987-95.

[56] Rose DP, Connolly JM. Effects of fatty acids and inhibitors of eicosanoid synthesis on the growth of a human breast cancer cell line in culture. Cancer Res 1990; 50(22): 7139-44.

[57] Hardy S, El-Assaad W, Przybytkowski E, Joly E, Prentki M, Langelier Y. Saturated fatty acid-induced apoptosis in MDA-MB231 breast cancer cells. A role for cardiolipin. J Biol Chem 2003; 278(34): 31861-70.

[58] Chajes V, Cambot M, Moreau K, Lenoir GM, Joulin V. AcetylCoA carboxylase alpha is essential to breast cancer cell survival. Cancer Res 2006; 66(10): 5287-94.

[59] Zhao H, Hardy RW. Long-chain saturated fatty acids induce annexin II translocation to detergent-resistant membranes. Biochem J 2004; 381(Pt 2): 463-9.

[60] Wicha MS, Liotta LA, Kidwell WR. Effects of free fatty acids on the growth of normal and neoplastic rat mammary epithelial cells. Cancer Res 1979; 39(2 Pt 1): 426-35

[61] Evans LM, Cowey SL, Siegal GP, Hardy RW. Stearate preferentially induces apoptosis in human breast cancer cells. Nutr Cancer 2009; 61(5): 746-53

[62] la Vecchia C, Negri E, Franceschi S, Decarli A, Giacosa A, Lipworth L. Olive oil, other dietary fats, and the risk of breast cancer (Italy). Cancer Causes Control 1995; 6(6): 545-50.

[63] Germain E, Chajes V, Cognault S, Lhuillery C, Bougnoux P. Enhancement of doxorubicin cytotoxicity by polyunsaturated fatty acids in the human breast tumor cell line MDA-MB-231: relationship to lipid peroxidation. Int J Cancer 1998; 75(4): 578-83.

[64] Przybytkowski E, Joly E, Nolan CJ, et al. Upregulation of cellular triacylglycerol - free fatty acid cycling by oleate is associated with long-term serum-free survival of human breast cancer cells. Biochem Cell Biol 2007; 85(3): 301-10.

[65] Menendez JA, Mehmi I, Atlas E, Colomer R, Lupu R. Novel signaling molecules implicated in tumor-associated fatty acid synthase-dependent breast cancer cell proliferation and survival: Role of exogenous dietary fatty acids, p53-p21WAF1/CIP1, ERK1/2 MAPK, p27KIP1, BRCA1, and NF-kappaB. Int J Oncol 2004; 24(3): 591-608.

[66] Navarro-Tito N, Robledo T, Salazar EP. Arachidonic acid promotes FAK activation and migration in MDA-MB-231 breast cancer cells. Exp Cell Res 2008; 314(18): 3340-55.

[67] Byon CH, Hardy RW, Ren C, et al. Free fatty acids enhance breast cancer cell migration through plasminogen activator inhibitor-1 and SMAD4. Lab Invest 2009; 89(11): 1221-8.
[68] Waterman E, Lockwood B. Active components and clinical applications of olive oil. Altern Med Rev 2007; 12(4): 331-42.

[69] Rose DP, Connolly JM. Stimulation of growth of human breast cancer cell lines in culture by linoleic acid. Biochem Biophys Res Commun 1989; 164(1): 277-83.

[70] Park Y, Allen KG, Shultz TD. Modulation of MCF-7 breast cancer cell signal transduction by linoleic acid and conjugated linoleic acid in culture. Anticancer Res 2000; 20(2A): 669-76.

[71] Reyes N, Reyes I, Tiwari R, Geliebter J. Effect of linoleic acid on proliferation and gene expression in the breast cancer cell line T47D. Cancer Lett 2004; 209(1): 25-35.

[72] Balakrishnan A, Cramer S, Bandyopadhyay GK, et al. Differential proliferative response to linoleate in cultures of epithelial cells from normal human breast and fibroadenomas. Cancer Res 1989; 49(4): 857-62.

[73] Connolly JM, Rose DP. Effects of fatty acids on invasion through reconstituted basement membrane ('Matrigel') by a human breast cancer cell line. Cancer Lett 1993; 75(2): 137-42.

[74] Liu XH, Rose DP. Stimulation of type IV collagenase expression by linoleic acid in a metastatic human breast cancer cell line. Cancer Lett 1994; 76(1): 71-7.

[75] Paine E, Palmantier R, Akiyama SK, Olden K, Roberts JD. Arachidonic acid activates mitogen-activated protein (MAP) kinase-activated protein kinase 2 and mediates adhesion of a human breast carcinoma cell line to collagen type IV through a p38 MAP kinase-dependent pathway. J Biol Chem 2000; 275(15): 11284-90.

[76] Kennett SB, Roberts JD, Olden K. Requirement of protein kinase C micro activation and calpain-mediated proteolysis for arachidonic acid-stimulated adhesion of MDA-MB-435 human mammary carcinoma cells to collagen type IV. J Biol Chem 2004; 279(5): 3300-7.

[77] Nony PA, Kennett SB, Glasgow WC, Olden K, Roberts JD. 15SLipoxygenase-2 mediates arachidonic acid-stimulated adhesion of human breast carcinoma cells through the activation of TAK1, MKK6, and p38 MAPK. J Biol Chem 2005; 280(36): 31413-9.

[78] Razanamahefa L, Prouff S, Bardon S. Stimulatory effect of arachidonic acid on T-47D human breast cancer cell growth is associated with enhancement of cyclin D1 mRNA expression. Nutr Cancer 2000; 38(2): 274-80

[79] Bocca C, Bozzo F, Martinasso G, Canuto RA, Miglietta A. Involvement of PPARalpha in the growth inhibitory effect of arachidonic acid on breast cancer cells. Br J Nutr 2008; 100(4): 739-50.

[80] Grammatikos SI, Subbaiah PV, Victor TA, Miller WM. n-3 and n-6 fatty acid processing and growth effects in neoplastic and noncancerous human mammary epithelial cell lines. Br J Cancer 1994; 70(2): 219-27.

[81] Horia E, Watkins BA. Comparison of stearidonic acid and alphalinolenic acid on PGE2 production and COX-2 protein levels in MDA-MB-231 breast cancer cell cultures. J Nutr Biochem 2005; 16(3): 184-92.

[82] Kim JY, Park HD, Park E, Chon JW, Park YK. Growth-inhibitory and proapoptotic effects of alpha-linolenic acid on estrogenpositive breast cancer cells. Ann N Y Acad Sci 2009; 1171: 190-5.

[83] Chamras H, Ardashian A, Heber D, Glaspy JA. Fatty acid modulation of MCF-7 human breast cancer cell proliferation, apoptosis and differentiation. J Nutr Biochem 2002; 13(12): 711-6.

[84] Chiu LC, Wong EY, Ooi VE. Docosahexaenoic acid from a cultured microalga inhibits cell growth and induces apoptosis by upregulating $\mathrm{Bax} / \mathrm{Bcl}-2$ ratio in human breast carcinoma MCF-7 cells. Ann N Y Acad Sci 2004; 1030: 361-8.

[85] Wu M, Harvey KA, Ruzmetov N, et al. Omega-3 polyunsaturated fatty acids attenuate breast cancer growth through activation of a neutral sphingomyelinase-mediated pathway. Int J Cancer 2005; 117(3): 340-8.

[86] Horia E, Watkins BA. Complementary actions of docosahexaenoic acid and genistein on COX-2, PGE2 and invasiveness in MDAMB-231 breast cancer cells. Carcinogenesis 2007; 28(4): 809-15.

[87] Sun H, Berquin IM, Owens RT, O'Flaherty JT, Edwards IJ Peroxisome proliferator-activated receptor gamma-mediated upregulation of syndecan-1 by n-3 fatty acids promotes apoptosis of human breast cancer cells. Cancer Res 2008; 68(8): 2912-9.

[88] Maheo K, Vibet S, Steghens JP, et al. Differential sensitization of cancer cells to doxorubicin by DHA: a role for lipoperoxidation. Free Radic Biol Med 2005; 39(6): 742-51. 
[89] Bonanome A, Grundy SM. Effect of dietary stearic acid on plasma cholesterol and lipoprotein levels. N Engl J Med 1988; 318(19): $1244-8$.

[90] Hanahan DJ. A Guide to Phospholipid Chemistry. New York: Oxford Univeristy Press 1997.

[91] Pearson TA. Stearic acid and cardiovascular disease - answers and questions. Am J Clin Nutr 1994; 60(Suppl): 1071S-2S.

[92] Kelly FD, Sinclair AJ, Mann NJ, Turner AH, Abedin L, Li D. A stearic acid-rich diet improves thrombogenic and atherogenic risk factor profiles in healthy males. Eur J Clin Nutr 2001; 55(2): 88-96.

[93] Louheranta AM, Turpeinen AK, Schwab US, Vidgren HM, Parviainen MT, Uusitupa MI. A high-stearic acid diet does not impair glucose tolerance and insulin sensitivity in healthy women. Metabolism 1998; 47(5): 529-34.

[94] Tholstrup T. Influence of stearic acid on hemostatic risk factors in humans. Lipids 2005; 40(12): 1229-35.

[95] Leung AW, Mak J, Cheung PS, Epstein RJ. Evidence for a programming effect of early menarche on the rise of breast cancer incidence in Hong Kong. Cancer Detect Prev 2008; 32(2): 156-61.

[96] Agriculture USDoHaHSaUSDo. Dietary Guidelines for Americans 2005. 2005 [cited 2009 February 10]; Available from: http://www.health.gov/DIETARYGUIDELINES/dga2005/docume nt/pdf/DGA2005.pdf

[97] Alo PL, Visca P, Marci A, Mangoni A, Botti C, Di Tondo U. Expression of fatty acid synthase (FAS) as a predictor of recurrence in stage I breast carcinoma patients. Cancer 1996; 77(3): 474-82.
[98] Lupu R, Menendez JA. Targeting fatty acid synthase in breast and endometrial cancer: An alternative to selective estrogen receptor modulators? Endocrinology 2006; 147(9): 4056-66.

[99] Hilakivi-Clarke L, Clarke R. Timing of dietary fat exposure and mammary tumorigenesis: role of estrogen receptor and protein kinase C activity. Mol Cell Biochem 1998; 188(1-2): 5-12.

[100] Boissonneault GA, Elson CE, Pariza MW. Net energy effects of dietary fat on chemically induced mammary carcinogenesis in F344 rats. J Natl Cancer Inst 1986; 76(2): 335-8.

[101] Willett W, Stampfer MJ. Total energy intake: implications for epidemiologic analyses. Am J Epidemiol 1986; 124(1): 17-27.

[102] Willett WC. Diet and cancer. Oncologist 2000; 5(5): 393-404.

[103] Key TJ, Appleby PN, Reeves GK, et al. Body mass index, serum sex hormones, and breast cancer risk in postmenopausal women. $\mathrm{J}$ Natl Cancer Inst 2003; 95(16): 1218-26.

[104] Peacock SL, White E, Daling JR, Voigt LF, Malone KE. Relation between obesity and breast cancer in young women. Am J Epidemiol 1999; 149(4): 339-46.

[105] Reeves GK, Pirie K, Beral V, Green J, Spencer E, Bull D. Cancer incidence and mortality in relation to body mass index in the Million Women Study: cohort study. BMJ 2007; 335(7630): 1134.

[106] Sweeney C, Blair CK, Anderson KE, Lazovich D, Folsom AR. Risk factors for breast cancer in elderly women. Am J Epidemiol 2004; 160(9): 868-75. 